\title{
Continuous use of glycomacropeptide in the nutritional management of patients with phenylketonuria: a clinical perspective
}

\author{
Maria João Pena ${ }^{1}$, Alex Pinto ${ }^{2,3}$, Manuela Ferreira de Almeida ${ }^{4,5,6}$, Catarina de Sousa Barbosa ${ }^{4,5}$, \\ Paula Cristina Ramos 4,5, Sara Rocha ${ }^{5}$, Arlindo Guimas ${ }^{5}$, Rosa Ribeiro ${ }^{5,6}$, Esmeralda Martins ${ }^{5,6}$, Anabela Bandeira ${ }^{5}$, \\ Cláudia Camila Dias ${ }^{7,8}$, Anita MacDonald² ${ }^{2}$ Nuno Borges ${ }^{7,9}$ and Júlio César Rocha $4,5,7,10^{*}$ (i)
}

\begin{abstract}
Background: In phenylketonuria (PKU), modified casein glycomacropeptide supplements (CGMP-AA) are used as an alternative to the traditional phenylalanine (Phe)-free L-amino acid supplements (L-AA). However, studies focusing on the long-term nutritional status of CGMP-AA are lacking. This retrospective study evaluated the long-term impact of CGMP-AA over a mean of 29 months in 11 patients with a mean age at CGMP-AA onset of 28 years (range 15-43) [8 females; 2 hyperphenylalaninaemia (HPA), 3 mild PKU, 3 classical PKU and 3 late-diagnosed]. Outcome measures included metabolic control, anthropometry, body composition and biochemical parameters.

Results: CGMP-AA, providing $66 \%$ of protein equivalent intake from protein substitute, was associated with no significant change in blood Phe with CGMP-AA compared with baseline $(562 \pm 289 \mu \mathrm{mol} / \mathrm{L}$ vs $628 \pm 317 \mu \mathrm{mol} / \mathrm{L} ; p=0.065)$. In contrast, blood tyrosine significantly increased on CGMP-AA $(52.0 \pm 19.2 \mu \mathrm{mol} / \mathrm{L}$ vs $61.4 \pm 23.8 \mu \mathrm{mol} / \mathrm{L} ; p=0.027)$.

Conclusions: Biochemical nutritional markers remained unchanged which is an encouraging finding in adults with PKU, many of whom are unable to maintain full adherence with nutritionally fortified protein substitutes. Longitudinal, prospective studies with larger sample sizes are necessary to fully understand the metabolic impact of using CGMPAA in PKU.
\end{abstract}

Keywords: Casein glycomacropeptide, Amino acids, Nutritional status, Phenylketonuria, Phenylalanine, Tyrosine

\section{Introduction}

Phenylketonuria (PKU, OMIM \# 261,600) is an inborn error of phenylalanine (Phe) metabolism caused by deficiency of phenylalanine hydroxylase [1]. PKU is successfully managed by a Phe-restricted diet supplemented with Phe-free L-amino acid supplements (L-AA) [2]. In recent years, casein glycomacropeptide (CGMP) has been prescribed as an alternative protein substitute in PKU. CGMP is a whey-based bioactive peptide derived

\footnotetext{
*Correspondence: rochajc@nms.unl.pt

${ }^{10}$ Nutrition and Metabolism, Nova Medical School, Faculdade de Ciências Médicas, Universidade Nova de Lisboa, 1169-056 Lisbon, Portugal Full list of author information is available at the end of the article
}

from the cheese-making process and it is potentially valuable for human health, particularly in PKU [3].

Commercial formulations of CGMP are supplemented with rate-limiting amino acids (CGMP-AA) as methionine, leucine (Leu), lysine, arginine, tyrosine (Tyr) and tryptophan [4] to improve their suitability in patients with PKU. However, a disadvantage of CGMP-AA compared with L-AA is that it contains some residual Phe. Most formulations contain around $36 \mathrm{mg}$ per $20 \mathrm{~g}$ protein equivalent [5].

In PKU, adherence to protein substitute is an ongoing challenge [6]. Recently, an Italian research group, using a survey to characterize the dietary habits of adult patients, original author(s) and the source, provide a link to the Creative Commons licence, and indicate if changes were made. The images or other third party material in this article are included in the article's Creative Commons licence, unless indicated otherwise in a credit line to the material. If material is not included in the article's Creative Commons licence and your intended use is not permitted by statutory regulation or exceeds the permitted use, you will need to obtain permission directly from the copyright holder. To view a copy of this licence, visit http://creativecommons.org/licenses/by/4.0/. The Creative Commons Public Domain Dedication waiver (http://creativeco mmons.org/publicdomain/zero/1.0/) applies to the data made available in this article, unless otherwise stated in a credit line to the data. 
showed that the intrinsic features of L-AA (e.g., palatability) are a cause of poor adherence [7]. In contrast, studies addressing the overall patient acceptability of CGMP-AA compared with their usual L-AA indicate good acceptance [8]. A sensory study suggested that CGMP-AA may enhance patients' adherence and therefore improve health status [9].

CGMP-AA has many functional and physiological properties. It acts as a prebiotic, increases the production of short-chain fatty acids (SCFA), has anti-inflammatory properties and exerts beneficial effects on bone, creating an attractive peptide for patients with PKU [10].

Over time, PKU treatment has been refined and optimized in order to avoid the negative effects on overall health status of low and inconsistent intake of a macroand micronutrient- supplemented L-AA [11]. However, studies addressing the long-term effect of CGMP-AA on nutritional status are lacking.

The purpose of the present study is to expand on previous data published by Pinto et al. [12] by increasing the duration of follow-up of a group of 11 patients with PKU taking CGMP-AA. In Pinto's study, blood Phe remained unchanged whereas blood Tyr increased whilst taking $57 \%$ of CGMP-AA as protein substitute in combination with L-AA [12]. A meta-analysis performed by our group also demonstrated no significant differences between CGMP-AA and L-AA for blood Phe and Tyr control in adults with PKU [8]. However, the use of CGMP-AA in children does adversely affect blood Phe control [13-15] and so there is concern about using CGMP-AA as the sole source of protein substitute in children and pregnancy. A first case report from our group revealed no deterioration of metabolic control during pregnancy when combined with L-AA [16]. A recent longitudinal, parallel, controlled study over 12 months assessing a formulation of CGMP-AA compared with L-AA on blood Phe, Tyr, Phe/Tyr ratio, biochemical nutritional status and growth in children with PKU identified no differences for the majority of the parameters that remained within the reference ranges, although CGMP-AA only provided $75 \%$ of the total protein substitute source. A significant increase in selenium and decrease in ferritin were observed [5].

The main aim of this study was to evaluate the longitudinal impact of the use of CGMP-AA in patients with PKU.

\section{Materials and methods}

\section{Study design and participants selection}

We conducted a retrospective longitudinal study of patients being treated for PKU and exclusively followedup at Centro de Genética Médica, Centro Hospitalar Universitário do Porto. Patients were given CGMP-AA as their primary nitrogen source if they had difficulties with taking L-AA or if CGMP-AA was considered a suitable alternative.

The inclusion criteria were diagnosis of PKU, absence of co-existent conditions and taking CGMP-AA as part of their protein substitute prescription. Exclusion criteria were the use of sapropterin, use of large neutral amino acids, pregnancy, lack of biochemical markers or body composition analysis.

All patients followed a low-Phe diet, avoiding high protein foods, and supplemented with L-AA and special low protein foods. Phe intake was controlled using a Phe exchange system ( 1 exchange $=20 \mathrm{mg}$ of Phe).

The present study included data on 11 patients from a previous study reported by Pinto et al. [12] but an extended follow-up period of 2.9 years if patients remained on CGMP-AA.

Data was collected between May 2013 and December 2018, whereas the previous study by Pinto et al. [12] retrieved data until February 2016. The first annual nutritional status evaluation (ANSE) was performed when taking L-AA and the last ANSE with the addition of CGMP-AA. The baseline assessment was conducted for a mean of 6 months before CGMP-AA commencement when patients were taking L-AA only as their primary nitrogen source. The last assessment was carried out when CGMP-AA had been given for a mean of 29 months. CGMP-AA either fully or partially replaced L-AA; CGMP-AA contribution to the total protein substitute intake was: $100 \%, n=4,50 \%$ to $<100 \%$, $n=4,<50 \%, n=3$. This was according to patient's protein substitute preference or by the nutritionist's prescription after assessing metabolic control, nutritional status, nutritional intake, anthropometry and body composition.

The PKU classification was based on the Portuguese guidelines as follows: hyperphenylalaninaemia (HPA) [blood Phe $<360 \mu \mathrm{mol} / \mathrm{L}(6 \mathrm{mg} / \mathrm{dL})$ ]; mild PKU [blood Phe $\geq 360 \mu \mathrm{mol} / \mathrm{L}$ and $\leq 1200 \mu \mathrm{mol} / \mathrm{L}$ ( $\geq 6 \mathrm{mg} / \mathrm{dL}$ and $\leq 20 \mathrm{mg} / \mathrm{dL}$ )] and classical PKU [blood Phe $>1200 \mu \mathrm{mol} / \mathrm{L}$ ( $>20 \mathrm{mg} / \mathrm{dL})$ ] [17].

Blood Phe and Tyr control was also evaluated over 2-time intervals as follows: i) from May 2013 until CGMP-AA introduction (13 \pm 5 months) and ii) from CGMP-AA introduction until the last ANSE taking CGMP-AA (29 \pm 16 months). The median number of blood Phe measurements while patients were taking L-AA was 11 (7-16) and with CGMP-AA was 40 (21-71).

The study design is presented in Fig. 1.

\section{Data collection and outcomes measured}

The following parameters were collected from patients' records by trained research nutritionists (M.J.P. and A.P.): 


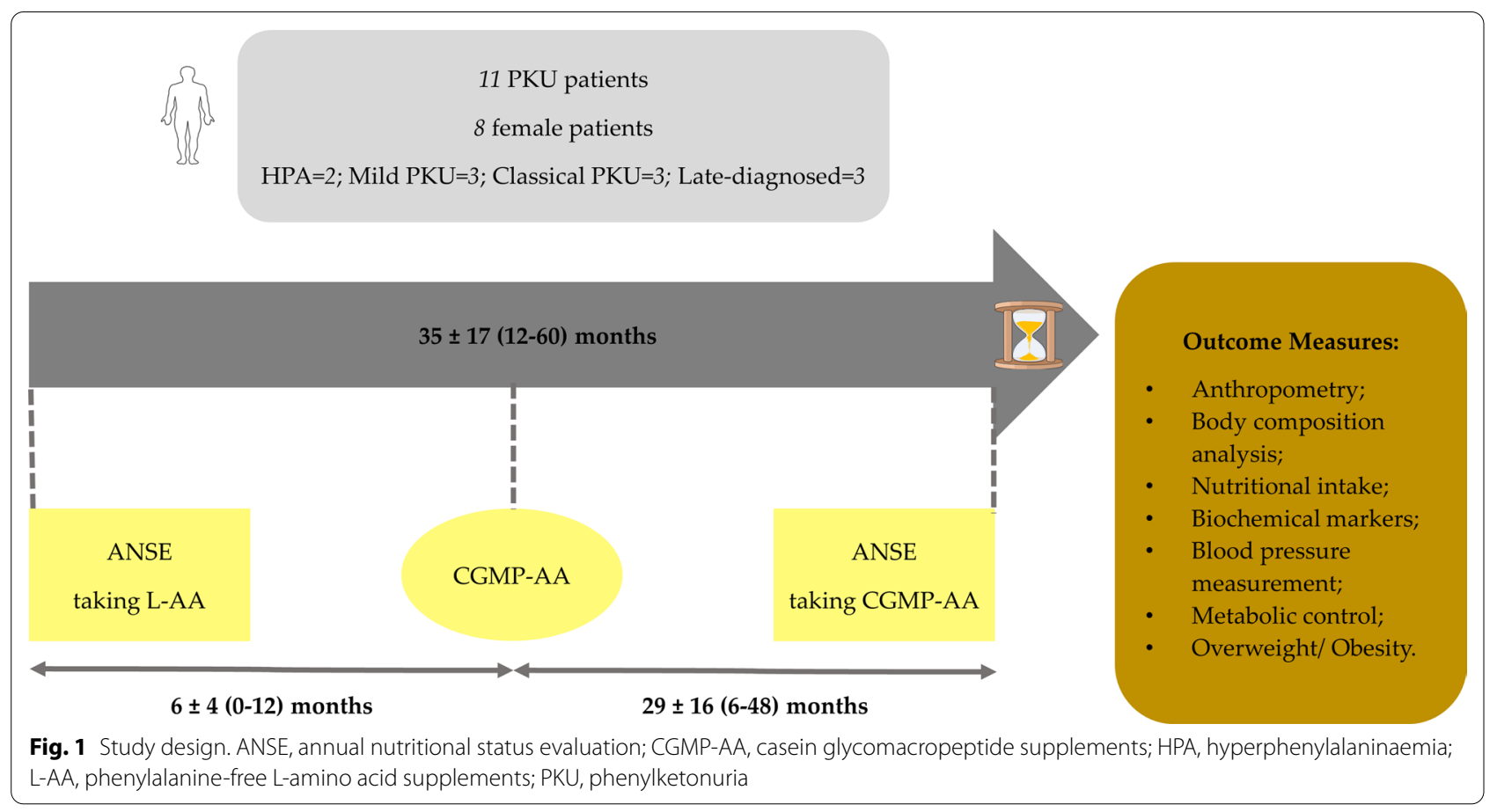

\section{Anthropometry}

Height $(\mathrm{cm})$ was measured with light clothes, using a stadiometer (SECA GmbH \& CO., Hamburg, Germany) (measured to the nearest millimetre) and weight $(\mathrm{kg})$ was assessed with a mechanical weighing scale (SECA GmbH \& CO., Hamburg, Germany) (measured to the nearest $100 \mathrm{~g})$. Waist circumference (WC) $(\mathrm{cm})$ was measured in the standing position, midway between the lower rib margin and the iliac crest, at the end of a normal exhalation, to the nearest millimetre and using a non-extensive metric tape. Anthropometric measures were performed by trained nutritionists (M.F.A. and J.C.R.).

\section{Body composition analysis}

Body composition was performed in the fasted state using a single-frequency $(50 \mathrm{~Hz})$ bioelectrical impedance analyzer, Akern, Quantum/S (RJL systems, Florence, Italy) according to described standards and measurement conditions. Total fat mass, percentage of body fat mass, percentage of lean mass and phase angle were assessed in the programme BodyGram ${ }^{\mathrm{TM}}$ version 1.3 (Akern Bioresearch, Florence, Italy) which uses validated prediction equations [18]. The measures were carried out by trained nutritionists (M.F.A. and J.C.R.).

\section{Nutritional intake}

Total protein intake, natural protein intake $(\mathrm{g} / \mathrm{kg} / \mathrm{day})$, protein equivalent from the protein substitute $(\mathrm{g} / \mathrm{kg} /$ day and $\mathrm{g} /$ day), Phe intake (mg/day) from both natural foods and CGMP-AA, Tyr (g/day) and Leu (g/day) intake from the protein substitutes were calculated using a 24-h food recall. Dietary assessments were performed by M.F.A. and J.C.R..

\section{Biochemical markers}

Blood samples for biochemical analysis were taken after an overnight fast. Uric acid, glucose, creatinine, urea, glycated haemoglobin $(\mathrm{HbA} 1 \mathrm{c})$, lipid panel [total cholesterol, triglycerides, high-density lipoprotein (HDL)cholesterol, low-density lipoprotein (LDL)-cholesterol, very low-density lipoproteins (VLDL)-cholesterol, apolipoprotein $\mathrm{A} 1$, apolipoprotein $\mathrm{B}]$, iron, transferrin, ferritin, albumin, homocysteine, prealbumin, C-reactive protein, insulin, calcium, phosphorus, selenium, zinc, vitamin B12, vitamin D and folic acid were determined. Blood urea nitrogen (BUN) was calculated from urea and homeostatic model of insulin resistance (HOMA-IR) was calculated as follows: HOMA-IR = fasting plasma glucose $(\mathrm{mg} / \mathrm{dL}) \times$ fasting serum insulin $(\mu \mathrm{U} / \mathrm{mL}) / 405[19]$.

\section{Blood pressure}

A Critikon Dinamap $^{\mathrm{TM}}$ vital signs monitor 8100 was used to measure resting systolic and diastolic blood pressure and heart rate with individuals seated for at least $5 \mathrm{~min}$, according to standard techniques. 


\section{Metabolic control}

Blood Phe and Tyr were measured by fasting blood spots and analysed by tandem mass spectrometry. Patients or Caregivers were trained to perform routine blood spots. Good metabolic control was defined as median blood Phe level within $120-360 \mu \mathrm{mol} / \mathrm{L}(2-6 \mathrm{mg} / \mathrm{dL}) \leq 12$ years or $120-480 \mu \mathrm{mol} / \mathrm{L}(2-8 \mathrm{mg} / \mathrm{dL})>12$ years of age, according to the Portuguese criteria [20]. The percentage of median blood Phe within the target range was also calculated.

\section{Overweight/obesity}

Body mass index (BMI) was calculated as the ratio of weight $(\mathrm{kg})$ and height $\left(\mathrm{m}^{2}\right)$ and classified according to the World Health Organisation (WHO) criteria. Overweight and obesity were defined when $\mathrm{BMI}$ was between 25.0 and $29.9 \mathrm{~kg} / \mathrm{m}^{2}$ or was $\geq 30.0 \mathrm{~kg} / \mathrm{m}^{2}$, respectively [21]. The Anthro Plus ${ }^{\circledR}$ programme version 1.0.4 was used to calculate the BMI z-scores for individuals under 19 years. Overweight and obesity were identified when the BMI z-score was between 1 and 2 standard deviations (S.D.) or above 2 S.D., respectively [22].

\section{Statistical analysis}

All statistical analyses were performed with SPSS $^{\circledR}$ version 26.0 for Mac (IBM Company, Chicago, IL, USA). Normal distribution was checked using Shapiro-Wilk test. Categorical variables are expressed as percentage and continuous variables as mean \pm S.D. or median (P25-P75) where appropriate. Paired t-test and Wilcoxon signed ranks test were used to analyse the differences when normal distribution or non-normal was found, respectively. The McNemar test was used to determine if there are differences on a dichotomous dependent variable between 2 related groups. Significance was set at the level of $p$ value less than 0.05 .

\section{Results}

\section{Characteristics of patients with PKU}

Table 1 summarizes the main features of the 11 patients included in this study ( 8 females and 3 males). The mean age at CGMP-AA onset was 28 years (range 15 to 43) (1 patient was $<18$ years: 15 years, $n=1$ ). In this cohort of patients, 2 of 11 had HPA, 3 mild PKU, 3 classical PKU and 3 were late-diagnosed. The mean length of time on CGMP-AA was 29 months (range 6 to 48).

\section{Nutritional intake}

Table 2 shows the type of protein substitute used in each assessment. The L-AA formulations prescribed were mainly powders and liquids. Subjects usually took more than one type of L-AA. The majority of patients $(n=9$; $82 \%$ ) were treated with the same formulation of CGMPAA, Glytactin BetterMilk ${ }^{\circledR}$ (Cambrooke, USA). Five of 11 patients took CGMP-AA for less than 2 years. The reasons why patients stopped taking CGMP-AA were poor dietary adherence $(n=1)$, temporary loss of follow-up $(n=1)$, sapropterin therapy $(n=2)$ and pregnancy $(n=1)$.

At the last ANSE, CGMP-AA contributed a mean of $66 \pm 31 \%$ (range 23 to 100 ) to the total protein substitute intake. The mean Phe provided by CGMP-AA was $44 \mathrm{mg} /$ day (range 23 to 73 ).

Table 1 Characteristics of patients with PKU included in the study

\begin{tabular}{|c|c|c|c|c|c|c|c|c|}
\hline Patient ID & $\begin{array}{l}\text { Blood Phe } \\
\text { levels at NBS } \\
(\mu \mathrm{mol} / \mathrm{L})\end{array}$ & Genotype & & $\begin{array}{l}\text { PKU } \\
\text { classification }\end{array}$ & $\begin{array}{l}\text { Age at ANSE } \\
\text { under L-AA } \\
\text { (years) }\end{array}$ & $\begin{array}{l}\text { Age } \\
\text { at CGMP-AA } \\
\text { start (years) }\end{array}$ & $\begin{array}{l}\text { Number } \\
\text { of months } \\
\text { taking } \\
\text { CGMP-AA }\end{array}$ & $\begin{array}{l}\text { Contribution } \\
\text { of CGMP-AA } \\
\text { to the total } \\
\text { protein } \\
\text { substitute } \\
\text { intake at last } \\
\text { assessment (\%) }\end{array}$ \\
\hline 1 & 240 & L249F & A300S & HPA & 17 & 18 & 6 & 100 \\
\hline 2 & $\mathrm{~N} / \mathrm{A}$ & $165 T$ & R270K & Late-diagnosed & 42 & 43 & 47 & 60 \\
\hline 3 & 720 & $165 T$ & $165 T$ & Mild PKU & 26 & 27 & 27 & 23 \\
\hline 4 & $\mathrm{~N} / \mathrm{A}$ & IVS10-11G>A & V388M & Late-diagnosed & 40 & 41 & 42 & 60 \\
\hline 5 & 1260 & IVS11+5G>A & $165 T$ & Classical PKU & 25 & 26 & 38 & 100 \\
\hline 6 & $\mathrm{~N} / \mathrm{A}$ & R158Q & $\mathrm{R} 252 \mathrm{~W}$ & Late-diagnosed & 37 & 38 & 7 & 27 \\
\hline 7 & 780 & $165 T$ & IVS10-11G>A & Mild PKU & 18 & 20 & 20 & 28 \\
\hline 8 & 2580 & IVS10-11G>A & IVS10-11G>A & Classical PKU & 24 & 27 & 48 & 100 \\
\hline 9 & 1260 & P281L & P281L & Classical PKU & 29 & 31 & 16 & 52 \\
\hline 10 & 420 & R261Q & E390G & HPA & 13 & 15 & 44 & 100 \\
\hline 11 & 840 & IVS10-11G>A & R270K & Mild PKU & 21 & 23 & 21 & 75 \\
\hline
\end{tabular}

ANSE, annual nutritional status evaluation; CGMP-AA, casein glycomacropeptide supplements; HPA, hyperphenylalaninaemia; ID, identification; L-AA, phenylalaninefree L-amino acid supplements; N/A, not available; NBS, newborn screening; Phe, phenylalanine; PKU, phenylketonuria 
Table 2 Type of protein substitute used in each assessment

\begin{tabular}{|c|c|c|c|}
\hline \multirow[t]{2}{*}{ Forms } & \multirow[t]{2}{*}{ L-AAt } & \multicolumn{2}{|l|}{ CGMP-AAt } \\
\hline & & L-AA & CGMP-AA \\
\hline Powders & $\begin{array}{l}\text { PKU } 3 \text { Advanta }{ }^{\circledR} \text { (Nutricia) }(n=4) \\
\text { PhenylAde }{ }^{\circledR} \text { (Taranis) }(n=2) \\
\text { PKU } 2 \text { Secunda }^{\circledR} \text { (Nutricia) }(n=1) \\
\text { PKU Anamix Junior }{ }^{\circledR} \text { (Nutricia) }(n=1) \\
\text { Phlexy } 10 \text { Drink Mix }{ }^{\circledR} \text { (Nutricia) }(n=1)\end{array}$ & PKU 3 Advanta ${ }^{\circledR}$ (Nutricia) $(n=2)$ & $\begin{array}{l}\text { Glytactin } \\
\text { BetterMilk }{ }^{\circledR} \\
\text { (Cam- }^{\text {brooke) }} \\
(n=9)\end{array}$ \\
\hline Liquids & $\begin{array}{l}\text { PKU Cooler } 10,15 \text { and } 20^{\circledR}(\text { Vitaflo) }(n=9) \\
\text { XPhe Jump } 10^{\circledR}(\text { MetaX) }(n=1)\end{array}$ & $\begin{array}{l}\text { PKU Cooler 10, } 15 \text { and } 20^{\circledR} \text { (Vitaflo) } \\
(n=5) \\
\text { PKU Lophlex LQ } 10^{\circledR} \text { (Nutricia) } \\
(n=1)\end{array}$ & $\begin{array}{l}\text { Glytactin RTD } \\
15^{\circledR} \text { (Cam- } \\
\text { brooke) } \\
(n=2) \\
\text { Glytactin RTD } \\
10^{\circledR}(\mathrm{Cam}- \\
\text { brooke) } \\
(n=3)\end{array}$ \\
\hline Bars & PhenylAde Amino Acid Bar ${ }^{\circledR}$ (Taranis) $(n=1)$ & & \\
\hline
\end{tabular}

CGMP-AA, casein glycomacropeptide supplements; L-AA, phenylalanine-free L-amino acid supplements; PKU, phenylketonuria; RTD, ready to drink; L-AAt, type of protein substitute when taking L-AA; CGMP-AAt, type of protein substitute when taking CGMP-AA

Table 3 describes metabolic control, nutritional intake, anthropometry and body composition of the participants when taking L-AA compared with CGMP-AA. The total amount of protein equivalent from protein substitute remained unchanged $[(0.86 \pm 0.24 \mathrm{~g} / \mathrm{kg} /$ day vs $0.74 \pm 0.23 \mathrm{~g} / \mathrm{kg} /$ day; $p=0.126)$ and $(50.8 \pm 16.3 \mathrm{~g} /$ day vs $44.6 \pm 12.8 \mathrm{~g} /$ day; $p=0.118)]$. The intake of Tyr was not affected with CGMP-AA $(5.18 \pm 1.77 \mathrm{~g} /$ day vs $4.22 \pm 1.59 \mathrm{~g} /$ day; $p=0.145)$. Natural protein and Phe ingestion stratified according to the percentage of CGMP-AA intake of the 11 patients with PKU taking L-AA vs CGMP-AA is shown in Additional file 1: Table S1.

\section{Anthropometry and body composition analysis}

Table 3 describes parameters of anthropometry and body composition of all patients taking L-AA compared with CGMP-AA. Patients on CGMP-AA had a tendency for increased body weight $(60.4 \pm 15.2 \mathrm{~kg}$ vs $63.4 \pm 13.2 \mathrm{~kg}$; $p=0.064)$ and total body fat $(17.3 \pm 13.5 \mathrm{~kg}$ vs $19.5 \pm 12.3 \mathrm{~kg} ; p=0.056)$ when compared to baseline with L-AA. However, the overall percentage of overweight and obesity in patients taking L-AA (46\%) vs CGMP-AA (46\%) remained unchanged $(p=1.000)$.

\section{Biochemical markers and blood pressure}

There were no differences in the biochemical and blood pressure data (Table 4).

\section{Metabolic control}

Table 3 describes metabolic control. Blood Phe concentrations were similar between baseline and CGMP-AA $(562 \pm 289 \mu \mathrm{mol} / \mathrm{L}$ vs $628 \pm 317 \mu \mathrm{mol} / \mathrm{L} ; p=0.065)$. The percentage of patients with median blood Phe within target range did not change ( $36 \%$ vs $36 \%, p=1.000)$. In the subgroup of patients with $100 \%$ CGMP-AA $(n=4)$, half of the patients had good metabolic control and the other half did not.

Blood Tyr significantly increased with CGMP-AA $(52.0 \pm 19.2 \mu \mathrm{mol} / \mathrm{L}$ vs $61.4 \pm 23.8 \mu \mathrm{mol} / \mathrm{L} ; p=0.027)$. Metabolic control stratified according to the percentage of CGMP-AA intake of the 11 patients with PKU taking L-AA vs CGMP-AA is shown in Additional file 1: Table S2.

Figures 2 and 3 show the metabolic control of Phe and Tyr control between baseline and the last assessment.

\section{Discussion}

This PKU study was the continuation of the work performed by Pinto et al. [12] and it is the only report describing the nutritional status of adults taking CGMPAA for a mean period of 2.4 years. CGMP-AA provided a mean $66 \%$ of the total protein substitute source (only 4 patients took $100 \%$ of protein substitute requirement as CGMP-AA), which was a small increase compared with the $57 \%$ from our previous report [12]. Only 6 of 11 patients took CGMP-AA for over 2 years.

There were no changes in blood Phe levels in this older cohort of patients with PKU, which is in line with the previous findings with CGMP-AA studies [12], although patients $\geq 12$ years of age maintained higher upper target blood Phe levels than children. In addition, half of our cohort had mild forms of PKU with a high Phe tolerance and so any extra Phe provided by CGMP-AA might not have affected the blood Phe levels [23]. Also, CGMP-AA only contributed partially to the total protein substitute 
Table 3 Overall metabolic control, nutritional intake, anthropometry and body composition of the 11 patients with PKU taking L-AA versus CGMP-AA

\begin{tabular}{|c|c|c|c|c|}
\hline Profile & $n$ & $T_{L-A A}$ & $\mathrm{~T}_{\text {CGMP-AA }}$ & $p$ value \\
\hline \multicolumn{5}{|l|}{ Metabolic control } \\
\hline Median blood Phe $(\mu \mathrm{mol} / \mathrm{L})$ & 11 & $562 \pm 289$ & $628 \pm 317$ & 0.065 \\
\hline Median blood Tyr ( $\mu \mathrm{mol} / \mathrm{L})$ & 11 & $52.0 \pm 19.2$ & $61.4 \pm 23.8$ & 0.027 \\
\hline Median blood Phe/Tyr ratio & 11 & $15.1 \pm 10.8$ & $12.0 \pm 8.8$ & 0.379 \\
\hline \multicolumn{5}{|l|}{ Nutritional intake } \\
\hline Natural protein intake (g/kg/day) & 11 & $0.41(0.26-0.62)$ & $0.34(0.21-0.69)$ & 0.657 \\
\hline Protein substitute (g/kg/day) & 11 & $0.86 \pm 0.24$ & $0.74 \pm 0.23$ & 0.126 \\
\hline Protein substitute (g/day) & 11 & $50.8 \pm 16.3$ & $44.6 \pm 12.8$ & 0.118 \\
\hline Phe intake (mg/day) & 11 & $885(751-1787)$ & $978(658-1370)$ & 0.721 \\
\hline Phe intake from protein substitute (mg/day) & 11 & 0 & $43.5 \pm 17.4$ & - \\
\hline Tyr intake from protein substitute (g/day) & 11 & $5.18 \pm 1.77$ & $4.22 \pm 1.59$ & 0.145 \\
\hline Leu intake from protein substitute (g/day) & 11 & $5.85(4.49-7.61)$ & $7.97(6.85-8.78)$ & 0.075 \\
\hline Protein (\%) & 11 & $13.8 \pm 2.25$ & $13.6 \pm 2.25$ & 0.696 \\
\hline Fat (\%) & 11 & $26.9 \pm 5.0$ & $27.6 \pm 4.2$ & 0.503 \\
\hline $\mathrm{CHO}(\%)$ & 11 & $57.0(52.1-60.1)$ & $58.5(55.8-60.2)$ & 0.248 \\
\hline Energy (kcal/day) & 11 & $2277 \pm 551$ & $2238 \pm 491$ & 0.793 \\
\hline \multicolumn{5}{|l|}{ Anthropometry and body composition } \\
\hline Weight (kg) & 11 & $60.4 \pm 15.2$ & $63.4 \pm 13.2$ & 0.064 \\
\hline Height (cm) & 11 & $158.6 \pm 6.4$ & $160.6 \pm 9.8$ & 0.341 \\
\hline WC (cm) & 11 & $85.1 \pm 15.2$ & $86.2 \pm 14.3$ & 0.536 \\
\hline $\operatorname{BMI}\left(\mathrm{kg} / \mathrm{m}^{2}\right)^{*}$ & 9 & $24.3 \pm 6.2$ & $25.1 \pm 5.6$ & 0.095 \\
\hline Body fat (kg) & 9 & $17.3 \pm 13.5$ & $19.5 \pm 12.3$ & 0.056 \\
\hline Body fat (\%) & 9 & $25.5 \pm 16.1$ & $28.9 \pm 13.4$ & 0.126 \\
\hline Lean mass (\%) & 9 & $74.5 \pm 16.1$ & $71.1 \pm 13.4$ & 0.126 \\
\hline Phase angle $\left(^{\circ}\right)$ & 9 & $6.8 \pm 0.7$ & $6.8 \pm 0.6$ & 0.880 \\
\hline
\end{tabular}

BMI, body mass index; CHO, carbohydrate; CGMP-AA, casein glycomacropeptide supplements; L-AA, phenylalanine-free L-amino acid supplements; Leu, leucine; Phe, phenylalanine; PKU, phenylketonuria; Tyr, tyrosine; $T_{L-A A}$, annual nutritional status evaluation under $L-A A ; T_{C G M P-A A}$ last annual nutritional status evaluation under CGMP-AA; WC, waist circumference. Data are presented as mean \pm S.D. (n) or median (P25-P75) (n). Paired t-test and Wilcoxon test were performed to identify differences when normal distribution or non-normal was found, respectively. Significance was set at the level of $p$ value less than 0.05 and highlighted in bold. ${ }^{*}$ Mean BMI was only calculated for adults

intake [24]. Finally, this was a small cohort of patients and the study was not powered to find a statistical change based on such small numbers.

Interestingly, an increase in blood Tyr was observed despite no difference in intake. The putative explanation for this finding can be related to better adherence with the protein substitute. Although L-AA contains higher amounts of Tyr compared to CGMP-AA, its bioavailability may be compromised due to lower solubility properties [25]. There is a suggestion that gut microbiota may contribute to less bioavailability of Tyr from L-AA [26], leading to lower blood Tyr levels. Considering diet is one of the main factors determining the gut microbiota which has been shown to interact with host metabolism [27], it is important to explore how the synthetic diet in PKU influences the configuration of the microbial community in the gut. It is possible that CGMP-AA also influences its composition. Theoretically, a diet poor or rich in certain nutrients may trigger an intestinal dysbiosis with systemic repercussions, such as obesity, diabetes, cancer, among others [28]. Studies sought to identify the effects of PKU diet on the microbiota are scarce, especially with CGMP-AA [26, 29].

In contrast to the Pinto et al. [12] study, HbA1c did not change in patients taking CGMP-AA. Even though, L-AA seems to lower glucose levels when compared to intact protein [30], further studies are needed to understand how chronic administration of protein substitute may influence glucose metabolism.

Biochemical biomarkers remained unchanged. BUN, a serum byproduct of protein metabolism that can be affected by dietary protein intake was similar to baseline on L-AA. This was comparable to previous reports [13, 31, 32] but also contradicts studies that found significantly lower levels with CGMP-AA [33, 34].

There was no impact on body composition and there was a trend for increased weight. The specific brand of CGMP-AA used by the majority of patients was higher 
Table 4 Blood pressure and biochemical data of patients at baseline compared with last assessment

\begin{tabular}{|c|c|c|c|c|}
\hline Profile & $n$ & $\mathrm{~T}_{\mathrm{L}-\mathrm{AA}}$ & $\mathrm{T}_{\text {CGMP-AA }}$ & $p$ value \\
\hline Systolic blood pressure (mmHg) & 11 & $112 \pm 13$ & $112 \pm 11$ & 1.000 \\
\hline Diastolic blood pressure $(\mathrm{mmHg})$ & 11 & $60 \pm 15$ & $63 \pm 12$ & 0.581 \\
\hline Heart rate (bpm) & 11 & $73 \pm 9$ & $72 \pm 8$ & 0.607 \\
\hline Uric acid (mg/dL) & 11 & $4.0 \pm 0.8$ & $4.0 \pm 1.2$ & 0.847 \\
\hline Glucose (mg/dL) & 11 & $78.2 \pm 6.8$ & $75.6 \pm 5.3$ & 0.190 \\
\hline Creatinine (mg/dL) & 11 & $0.7 \pm 0.1$ & $0.7 \pm 0.1$ & 0.676 \\
\hline Urea (mg/dL) & 11 & $20.5 \pm 7.6$ & $23.2 \pm 6.7$ & 0.262 \\
\hline BUN (mg/dL) & 11 & $1.68 \pm 0.63$ & $1.90 \pm 0.55$ & 0.268 \\
\hline $\mathrm{HbA1c}(\%)$ & 10 & $5.1 \pm 0.4$ & $5.0 \pm 0.3$ & 0.107 \\
\hline Total cholesterol (mg/dL) & 11 & $165 \pm 37$ & $156 \pm 34$ & 0.349 \\
\hline $\mathrm{HDL}-\mathrm{C}(\mathrm{mg} / \mathrm{dL})$ & 11 & $55 \pm 14$ & $51 \pm 11$ & 0.194 \\
\hline $\mathrm{LDL}-\mathrm{C}(\mathrm{mg} / \mathrm{dL})$ & 11 & $93 \pm 32$ & $85 \pm 32$ & 0.265 \\
\hline VLDL-C (mg/dL) & 11 & $17 \pm 6$ & $20 \pm 10$ & 0.121 \\
\hline Triglycerides (mg/dL) & 11 & $84 \pm 27$ & $99 \pm 50$ & 0.140 \\
\hline ApoA1 (mg/dL) & 10 & $153 \pm 25$ & $145 \pm 31$ & 0.187 \\
\hline ApoB (mg/dL) & 10 & $82 \pm 22$ & $80 \pm 22$ & 0.612 \\
\hline Iron ( $\mu \mathrm{g} / \mathrm{dL})$ & 11 & $115(85-135)$ & $88(48-144)$ & 0.266 \\
\hline Transferrin (mg/dL) & 11 & $271 \pm 43$ & $263 \pm 44$ & 0.554 \\
\hline Ferritin (ng/dL) & 11 & $65 \pm 35$ & $52 \pm 26$ & 0.132 \\
\hline Albumin (g/dL) & 11 & $4.69 \pm 0.33$ & $4.57 \pm 0.17$ & 0.112 \\
\hline Homocysteine $(\mu \mathrm{mol} / \mathrm{L})$ & 8 & $8.44 \pm 1.51$ & $8.21 \pm 1.32$ & 0.820 \\
\hline Prealbumin (mg/dL) & 11 & $240(224-278)$ & $272(200-293)$ & 0.575 \\
\hline CRP (mg/dL) & 10 & $0.89(0.72-2.46)$ & $1.28(0.77-2.92)$ & 0.799 \\
\hline Insulin $(\mu \mathrm{U} / \mathrm{mL})$ & 8 & $7.8(7.3-13.6)$ & $9.8(6.5-18.3)$ & 0.161 \\
\hline HOMA-IR & 8 & $1.5(1.4-2.5)$ & $1.8(1.2-3.5)$ & 0.327 \\
\hline Calcium (mmol/L) & 11 & $2.37 \pm 0.12$ & $2.33 \pm 0.11$ & 0.164 \\
\hline Phosphorus (mmol/L) & 11 & $1.07 \pm 0.24$ & $0.98 \pm 0.14$ & 0.221 \\
\hline Selenium ( $\mu \mathrm{mol} / \mathrm{L})$ & 6 & $0.70 \pm 0.30$ & $0.96 \pm 0.31$ & 0.257 \\
\hline Zinc $(\mu \mathrm{mol} / \mathrm{L})$ & 11 & $12.5(9.7-17.4)$ & $11.3(10.4-12.4)$ & 0.155 \\
\hline Vit. B12 (pg/L) & 11 & $484(413-734)$ & $459(301-1043)$ & 0.722 \\
\hline Vit. D (nmol/L) & 11 & $77 \pm 26$ & $70 \pm 27$ & 0.153 \\
\hline Folic acid (ng/mL) & 9 & $12.9 \pm 3.8$ & $12.9 \pm 5.3$ & 0.996 \\
\hline
\end{tabular}

ApoA1, apolipoprotein A1; ApoB, apolipoprotein B; BUN, blood urea nitrogen; CGMP-AA, casein glycomacropeptide supplements; C, cholesterol; CRP, c-reactive protein; HbA1c, glycated haemoglobin; HDL-C, high-density lipoprotein-cholesterol; HOMA-IR, homeostatic model of insulin resistance; L-AA, phenylalanine-free L-amino acid supplements; LDL-C, low-density lipoprotein-cholesterol; Phe, phenylalanine; PKU, phenylketonuria; Tyr, tyrosine; $T_{L-A A}$, nutritional status evaluation

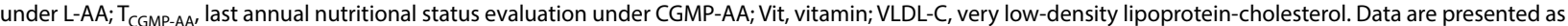
mean \pm S.D. ( $n$ ) or median (P25-P75) (n). Paired t-test and Wilcoxon test were performed to identify differences when normal distribution or non-normal was found, respectively. Significance was set at the level of $p$ value less than 0.05

in energy compared with the L-AA given. There is suggestion that CGMP-AA increases satiety and a similar energy intake between baseline and the last assessment was observed [35]. However, any change in weight should be interpreted carefully. In this study, patient numbers were small and data on physical activity was not collected. Daly et al. studied a group of children taking CGMP-AA vs L-AA over 12 months. They found no differences between CGMP-AA and L-AA for anthropometry at each of the measured time points but within the CGMP-AA group, weight and BMI z-scores increased significantly between baseline to 12 months [5].

The results from our study are very encouraging about the use of CGMP-AA in adult patients with PKU. It is well established that dietary non-adherence increases with age, commonly reflecting poor tolerance of the protein substitute [6]. The restrictive nature of the PKU diet as well as inadequate adherence with the fortified protein substitute is likely to cause sub-optimal nutritional intake and increase the risk of clinical and biochemical nutritional deficiencies [36]. In this study, CGMP-AA enabled 


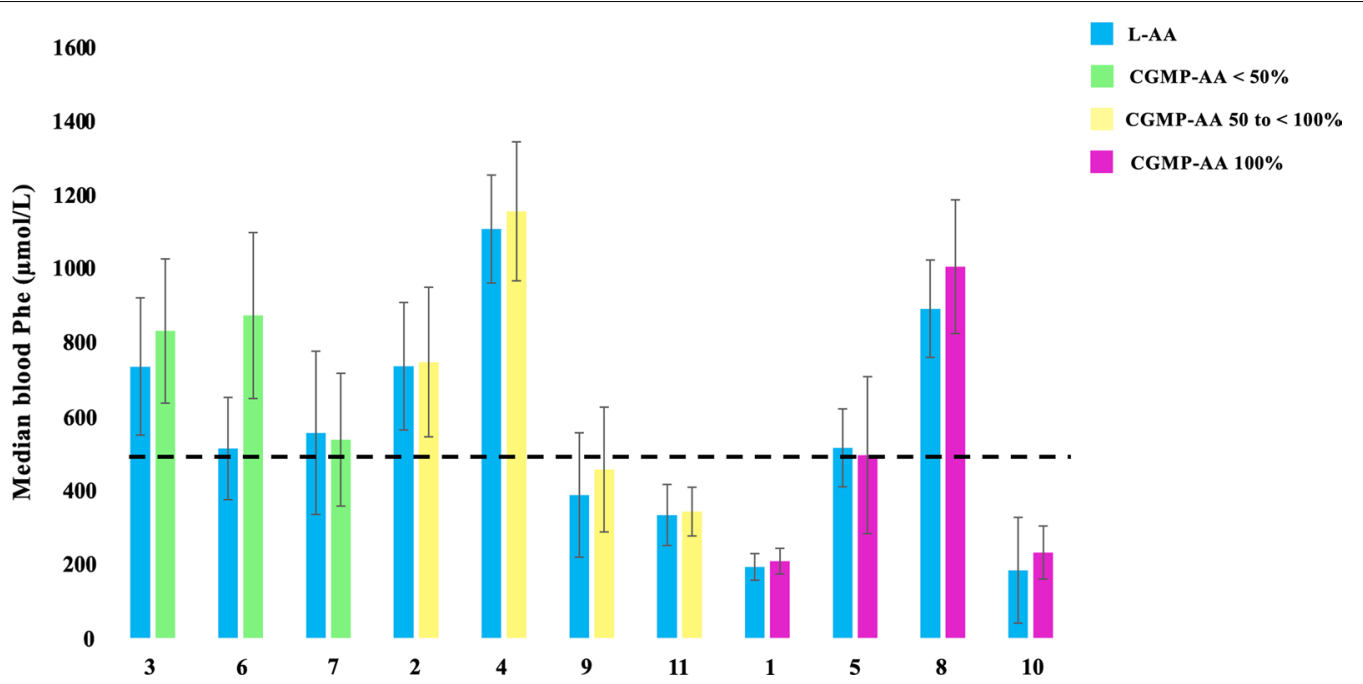

Fig. 2 Median blood Phe levels of 11 patients with PKU taking L-AA versus CGMP-AA (last ANSE) with different percentages of contribution to the total protein substitute. CGMP-AA, casein glycomacropeptide supplements; L-AA, phenylalanine-free L-amino acid supplements; Phe, phenylalanine. Dashed line: target level of $480 \mu \mathrm{mol} / \mathrm{L}>12$ years. The number below each pair of bars represents Patient ID

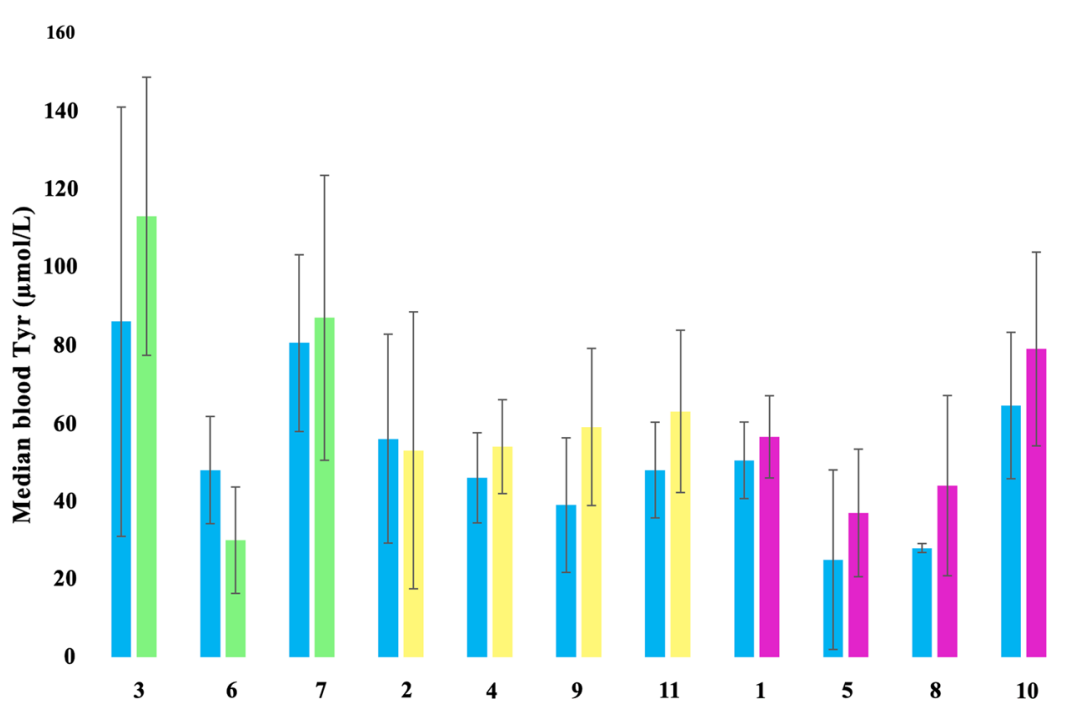

Fig. 3 Median blood Tyr levels of 11 patients with PKU taking L-AA versus CGMP-AA (last ANSE) with different percentages of contribution to the total protein substitute. CGMP-AA, casein glycomacropeptide supplements; L-AA, phenylalanine-free L-amino acid supplements; Tyr, tyrosine. The number below each pair of bars represents Patient ID

many adult patients to successfully remain on dietary treatment. Only 1 of 5 patients stopped taking CGMPAA due to poor adherence.

Our findings do have several limitations. Although we collected data over 6 years, the sample size is still small and only 55\% (6 out 11 patients) of the patient cohort had $>2$ years follow-up whilst taking CGMP-AA. Also, not all the patients replaced their full prescription of L-AA intake with CGMP-AA. In addition, the severity

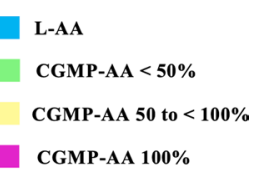

CGMP-AA $100 \%$ 
by a 24-h food recall method, and like other dietary assessment methods it is associated with disadvantages.

\section{Conclusions}

With this long-term work we can clearly state that the metabolic control and the biochemical nutritional status of patients with PKU did not deteriorate with time, but only 6 patients remained on CGMP-AA $>2$ years duration. In addition, parameters of body composition and the percentage of overweight and obesity did not significantly increase while taking CGMP-AA for a longer follow-up period.

This work suggests that CGMP-AA is safe and does not affect nutritional status even though it would be useful to have more studies replicating these results with a higher sample of patients. So far, the only difference observed to traditional L-AA is improved palatability which may contribute to better long-term adherence with protein substitute.

\section{Supplementary Information}

The online version contains supplementary material available at https://doi. org/10.1186/s13023-021-01721-8.

Additional file 1. Supplementary data.

\section{Abbreviations}

ANSE: Annual nutritional status evaluation; ApoA1: Apolipoprotein A1; ApoB: Apolipoprotein B; BMI: Body mass index; BUN: Blood urea nitrogen; CGMP: Casein glycomacropeptide; CGMP-AA: Casein glycomacropeptide supplements; C: Cholesterol; CHO: Carbohydrate; CRP: C-reactive protein; HbA1 c: Glycated haemoglobin; HDL-C: High-density lipoprotein-cholesterol; HOMA-IR: Homeostatic model of insulin resistance; HPA: Hyperphenylalaninaemia; L-AA: Phenylalanine (Phe)-free L-amino acid supplements; Leu: Leucine; LDL-C: Lowdensity lipoprotein-cholesterol; NBS: Newborn screening; Phe: Phenylalanine; PKU: Phenylketonuria; RTD: Ready to drink; SCFA: Short-chain fatty acids; SD: Standard deviation; T CGMP-AA: Last annual nutritional status evaluation under CGMP-AA; TLAA: Nutritional status evaluation under L-AA; Tyr: Tyrosine; VLDL-C: Very low-density lipoprotein-cholesterol; Vit: Vitamin; WC: Waist circumference; WHO: World Health Organisation.

\section{Acknowledgements}

M.J.P. was partially funded by the project NORTE-08-5369-FSE-000018, supported by Norte Portugal Regional Programme (Norte2020), under the PORTUGAL 2020 Partnership Agreement, through the European Regional Development Fund (ERDF).

\section{Authors' contributions}

All authors read and approved the final manuscript. All the authors were involved in data collection, interpretation of data, critical revision of the paper for important intellectual content and approval of the final version. M.J.P. was involved in all steps of the manuscript. A.P. was involved in project design, collection of data and critical appraisal of the manuscript. N.B. was involved in data analysis and give a valuable contribution to the revision of the manuscript. J.C.R. conceived and designed the study and was in charge of planning.

\section{Funding}

This article was funded by the project NORTE-08-5369-FSE-000018, supported by Norte Portugal Regional Programme (Norte2020), under the PORTUGAL 2020 Partnership Agreement, through the European Regional Development Fund (ERDF) and by FCT_Fundação para a Ciência e a Tecnologia [UID/ BIM/04293/2013].

\section{Availability of data and materials}

The datasets during and/or analysed during the current study available from the corresponding author on reasonable request.

\section{Ethics approval and consent to participate}

This study was approved by the Ethics Committee of Centro de Genética Médica, Centro Hospitalar Universitário do Porto, on 18th May 2015, under the umbrella of the project TNSPKU (Trends in Nutritional Status of Patients with Phenylketonuria), with the reference 2015.101 (092-DEFI/087-CES). Written informed consent was obtained from each patient or caregiver (age dependent) during the routine nutritional appointment.

\section{Consent for publication}

Not applicable.

\section{Competing interests}

A.P. has received an educational grant from Cambrooke Therapeutics and grants from Vitaflo, Nutricia, Merck Serono, BioMarin, and Mevalia to attend scientific meetings. M.F.A. received grants from Glutamine, Nutricia, Merck Serono, BioMarin, Orphan, and Lifediet to attend congress and for education. A.M. has received research funding and honoraria from Nutricia, Vitaflo International, BioMarin, Mevalia, and Pharma Galen. She is a member of the European Nutrition Expert Panel (BioMarin), and a member of the following advisory boards: the European PKU Group Board (BioMarin), Element (Danone-Nutricia), Excemed, Arla, and Applied Pharma Research. J.C.R. is member of the European Nutrition Expert Panel (BioMarin) and of the advisory boards of Applied Pharma Research and Nutricia. He has received speaker's fees from Applied Pharma Research, Merck Serono, BioMarin, Nutricia, Vitaflo, Cambrooke, PIAM, and Lifediet.

\section{Author details}

${ }_{1}^{1}$ Departamento de Biomedicina, Unidade de Bioquímica, Faculdade de Medicina, Universidade do Porto, 4200-319 Porto, Portugal. ${ }^{2}$ Department of Dietetics, Birmingham Children's Hospital, Birmingham B4 6NH, UK. ${ }^{3}$ Faculty of Health and Human Sciences, University of Plymouth, Plymouth PL6 8BH, UK. ${ }^{4}$ Centro de Genética Médica, Centro Hospitalar Universitário Do Porto (CHUP), 4099-028 Porto, Portugal. ${ }^{5}$ Centro de Referência na área das Doenças Hereditárias do Metabolismo, CHUP, 4099-001 Porto, Portugal. ${ }^{6}$ UMIB/ICBAS/ UP), Unit for Multidisplinary Research in Biomedicine, Abel Salazar Institute of Biomedical Sciences, University of Porto, 4050-313 Porto, Portugal. ${ }^{7}$ Center for Health Technology and Services Research (CINTESIS), 4200-450 Porto, Portugal. ${ }^{8}$ Department of Community Medicine, Information and Health Sciences (MEDCIDS), Faculty of Medicine, University of Porto, 4200-450 Porto, Portugal. ${ }^{9}$ Faculdade de Ciências da Nutrição e Alimentação, Universidade do Porto, 4150-180 Porto, Portugal. ${ }^{10}$ Nutrition and Metabolism, Nova Medical School, Faculdade de Ciências Médicas, Universidade Nova de Lisboa, 1169-056 Lisbon, Portugal.

Received: 5 November 2020 Accepted: 2 February 2021

Published online: 13 February 2021

\section{References}

1. Blau N, van Spronsen FJ, Levy HL. Phenylketonuria. Lancet. 2010;376(9750):1417-27.

2. Rocha JC, MacDonald A. Dietary intervention in the management of phenylketonuria: current perspectives. Pediatric Health Med Ther. 2016;7:155-63.

3. Macleod EL, Ney DM. Nutritional management of phenylketonuria. Ann Nestle Eng. 2010;68(2):58-69.

4. Laclair CE, Ney DM, MacLeod EL, Etzel MR. Purification and use of glycomacropeptide for nutritional management of phenylketonuria. J Food Sci. 2009;74(4):E199-206.

5. Daly A, Evans S, Chahal S, Santra S, Pinto A, Jackson R, et al. Glycomacropeptide: long-term use and impact on blood phenylalanine, growth and nutritional status in children with PKU. Orphanet J Rare Dis. 2019;14(1):44.

6. MacDonald A, Gokmen-Ozel H, van Rijn M, Burgard P. The reality of dietary compliance in the management of phenylketonuria. J Inherit Metab Dis. 2010;33(6):665-70 
7. Ford S, O'Driscoll M, MacDonald A. Living with Phenylketonuria: Lessons from the PKU community. Mol Genet Metab Rep. 2018;17:57-63.

8. Pena MJ, Pinto A, Daly A, MacDonald A, Azevedo L, Rocha JC, et al. The use of glycomacropeptide in patients with phenylketonuria: a systematic review and meta-analysis. Nutrients. 2018;10(11):1794.

9. Proserpio C, Pagliarini E, Zuvadelli J, Paci S, Re Dionigi A, Banderali G, et al. Exploring drivers of liking of low-phenylalanine products in subjects with phenyilketonuria using check-all-that-apply method. Nutrients. 2018:10(9):1179.

10. Ney DM, Etzel MR. Designing medical foods for inherited metabolic disorders: why intact protein is superior to amino acids. Curr Opin Biotechnol. 2017:44:39-45.

11. MacDonald A, Singh RH, Rocha JC, van Spronsen FJ. Optimising amino acid absorption: essential to improve nitrogen balance and metabolic control in phenylketonuria. Nutr Res Rev. 2019;32(1):70-8.

12. Pinto A, Almeida MF, Ramos PC, Rocha S, Guimas A, Ribeiro R, et al. Nutritional status in patients with phenylketonuria using glycomacropeptide as their major protein source. Eur J Clin Nutr. 2017;71(10):1230-4.

13. Zaki OK, El-Wakeel L, Ebeid Y, Ez Elarab HS, Moustafa A, Abdulazim N, et al. The use of glycomacropeptide in dietary management of phenylketonuria. J Nutr Metab. 2016;2016:2453027.

14. Daly A, Evans S, Chahal S, Santra S, MacDonald A. Glycomacropeptide in children with phenylketonuria: does its phenylalanine content affect blood phenylalanine control? J Hum Nutr Diet. 2017;30(4):515-23.

15. Daly A, Evans S, Chahal S, Santra S, Pinto A, Gingell C, et al. The effect of glycomacropeptide versus amino acids on phenylalanine and tyrosine variability over 24 hours in children with PKU: a randomized controlled trial. Nutrients. 2019;11(3):520.

16. Pinto A, Almeida MF, Cunha A, Carmona C, Rocha S, Guimas A, et al. Dietary management of maternal phenylketonuria with glycomacropeptide and amino acids supplements: a case report. Mol Genet Metab Rep. 2017;13:105-10

17. Rocha JC, Vilarinho L, Cabral A, Osório RV, Almeida MF. Consensus for the nutritional treatment of phenylketonuria. Acta Pediatr Port. 2007;38(1):44-54.

18. Sun SS, Chumlea WC, Heymsfield SB, Lukaski HC, Schoeller D, Friedl K, et al. Development of bioelectrical impedance analysis prediction equations for body composition with the use of a multicomponent model for use in epidemiologic surveys. Am J Clin Nutr. 2003;77(2):331-40.

19. Li JC, Wu DA, Hou JS, Subeq YM, Chen HD, Hsu BG. High serum adipocyte fatty acid binding protein is associated with metabolic syndrome in patients with type 2 diabetes. J Diabetes Res. 2016:2016:8380279.

20. Sousa C, Almeida MF, Sousa Barbosa C, Martins E, Janeiro P, Tavares de Almeida I, et al. The European Phenylketonuria Guidelines and the challenges on management practices in Portugal. J Pediatr Endocrinol Metab. 2019:32(6):623-9.

21. Obesity: preventing and managing the global epidemic. Report of a WHO consultation. World Health Organ Tech Rep Ser. 2000;894:i-xii, $1-253$.

22. de Onis M, Onyango AW, Borghi E, Siyam A, Nishida C, Siekmann J. Development of a WHO growth reference for school-aged children and adolescents. Bull World Health Organ. 2007;85(9):660-7.

23. Pinto A, Almeida MF, MacDonald A, Ramos PC, Rocha S, Guimas A, et al, Over restriction of dietary protein allowance: the importance of ongoing reassessment of natural protein tolerance in phenylketonuria. Nutrients. 2019;11(5):995.
24. Hochuli M, Bollhalder S, Thierer C, Refardt J, Gerber P, Baumgartner MR. Effects of inadequate amino acid mixture intake on nutrient supply of adult patients with phenylketonuria. Ann Nutr Metab. 2017;71(3-4):129-35.

25. Grunert SC, Brichta CM, Krebs A, Clement HW, Rauh R, Fleischhaker C, et al. Diurnal variation of phenylalanine and tyrosine concentrations in adult patients with phenylketonuria: subcutaneous microdialysis is no adequate tool for the determination of amino acid concentrations. Nutr J. 2013;12:60.

26. Ney DM, Murali SG, Stroup BM, Nair N, Sawin EA, Rohr F, et al. Metabolomic changes demonstrate reduced bioavailability of tyrosine and altered metabolism of tryptophan via the kynurenine pathway with ingestion of medical foods in phenylketonuria. Mol Genet Metab. 2017:121(2):96-103.

27. Allin $\mathrm{KH}$, Nielsen T, Pedersen O. Mechanisms in endocrinology: Gut microbiota in patients with type 2 diabetes mellitus. Eur J Endocrinol. 2015;172(4):R167-77.

28. Colonetti K, Roesch LF, Schwartz IVD. The microbiome and inborn errors of metabolism: Why we should look carefully at their interplay? Genet Mol Biol. 2018:41(3):515-32.

29. Sawin EA, De Wolfe TJ, Aktas B, Stroup BM, Murali SG, Steele JL, et al. Glycomacropeptide is a prebiotic that reduces Desulfovibrio bacteria, increases cecal short-chain fatty acids, and is anti-inflammatory in mice. Am J Physiol Gastrointest Liver Physiol. 2015;309(7):G590-601.

30. Pena MJ, Guerreiro SG, Rocha JC, Morais T, Pereira SS, Monteiro MP, et al. Acute effect of an amino acid mixture in the rat glycemic profile. J Cell Biochem. 2019:120(8):13056-65.

31. Ahring KK, Lund AM, Jensen E, Jensen TG, Brondum-Nielsen K, Pedersen $M$, et al. Comparison of glycomacropeptide with phenylalanine freesynthetic amino acids in test meals to PKU patients: no significant differences in biomarkers, including plasma Phe levels. J Nutr Metab. 2018:2018:6352919

32. Ney DM, Stroup BM, Clayton MK, Murali SG, Rice GM, Rohr F, et al. Glycomacropeptide for nutritional management of phenylketonuria: a randomized, controlled, crossover trial. Am J Clin Nutr. 2016;104(2):334-45.

33. MacLeod EL, Clayton MK, van Calcar SC, Ney DM. Breakfast with glycomacropeptide compared with amino acids suppresses plasma ghrelin levels in individuals with phenylketonuria. Mol Genet Metab. 2010;100(4):303-8.

34. van Calcar SC, MacLeod EL, Gleason ST, Etzel MR, Clayton MK, Wolff JA, et al. Improved nutritional management of phenylketonuria by using a diet containing glycomacropeptide compared with amino acids. Am J Clin Nutr. 2009;89(4):1068-77.

35. van Calcar SC, Ney DM. Food products made with glycomacropeptide, a low-phenylalanine whey protein, provide a new alternative to amino Acid-based medical foods for nutrition management of phenylketonuria. J Acad Nutr Diet. 2012;112(8):1201-10

36. Montoya Parra GA, Singh RH, Cetinyurek-Yavuz A, Kuhn M, MacDonald A. Status of nutrients important in brain function in phenylketonuria: a systematic review and meta-analysis. Orphanet J Rare Dis. 2018;13(1):101.

\section{Publisher's Note}

Springer Nature remains neutral with regard to jurisdictional claims in published maps and institutional affiliations. 